Meta

Journal des traducteurs

Translators' Journal

\title{
Traducción como red colaborativa hacia la subalternidad (Benítez, Ortese y Macciocchi: un caso de empoderamiento y affidamento en traducción)
}

\section{Belén Ruiz Molina}

Volume 56, numéro 3, septembre 2011

URI : https://id.erudit.org/iderudit/1008336ar

DOI : https://doi.org/10.7202/1008336ar

Aller au sommaire du numéro

\section{Éditeur(s)}

Les Presses de l’Université de Montréal

\section{ISSN}

0026-0452 (imprimé)

1492-1421 (numérique)

\section{Découvrir la revue}

\section{Citer cet article}

Ruiz Molina, B. (2011). Traducción como red colaborativa hacia la subalternidad (Benítez, Ortese y Macciocchi: un caso de empoderamiento y affidamento en traducción). Meta, 56(3), 610-630.

https://doi.org/10.7202/1008336ar

\section{Résumé de l'article}

La multidisciplinarité de la traductologie nous permet d'aborder, selon différentes perspectives théoriques, les phénomènes qui se produisent dans la pratique de la traduction. Les dernières tendances idéologiques envisagent la relation entre traduction et genre. Dans ce cadre, nous nous intéressons à l'engagement manifesté, par certaines traductrices, à l'égard de la traduction de la littérature féminine ainsi que des relations qui s'établissent entre auteure et traductrice. À partir des définitions d'autonomisation (empoderamiento) dans le domaine de la coopération et du développement, et des travaux sur la responsabilisation (affidamento) et la traduction, la présente étude se concentre sur le travail d'Esther Benítez, traductrice d'Anna María Ortese et de Maria Antonietta Macciocchi, et sur sa pratique de la traduction comme réseau de collaboration. De la relation entre les deux écrivaines italiennes et du contact qu'elles ont toutes deux maintenu avec Benítez, nous tenterons de mettre en lumière des nouvelles dimensions des concepts de subalternité (subalternidad), d'autonomisation et de responsabilisation. Esther Benítez, traductrice très réputée du français et de l'italien (ce qui lui a valu le Premio Nacional de Traducción en 1992, en reconnaissance de toute son oeuvre) en espagnol, a produit en parallèle un riche appareil critique (articles, préfaces, ateliers...), autant de sources paratextuelles dont nous extrayons les données traductologiques qui fondent notre étude. 


\title{
Traducción como red colaborativa hacia la subalternidad (Benítez, Ortese y Macciocchi: un caso de empoderamiento y affidamento en traducción)
}

\author{
BELÉN RUIZ MOLINA \\ Universitat Jaume I de Castelló, Castelló de la Plana, España \\ belenruizmolina@hotmail.com
}

\begin{abstract}
RÉSUMÉ
La multidisciplinarité de la traductologie nous permet d'aborder, selon différentes perspectives théoriques, les phénomènes qui se produisent dans la pratique de la traduction. Les dernières tendances idéologiques envisagent la relation entre traduction et genre. Dans ce cadre, nous nous intéressons à l'engagement manifesté, par certaines traductrices, à l'égard de la traduction de la littérature féminine ainsi que des relations qui s'établissent entre auteure et traductrice. À partir des définitions d'autonomisation (empoderamiento) dans le domaine de la coopération et du développement, et des travaux sur la responsabilisation (affidamento) et la traduction, la présente étude se concentre sur le travail d'Esther Benítez, traductrice d'Anna María Ortese et de Maria Antonietta Macciocchi, et sur sa pratique de la traduction comme réseau de collaboration. De la relation entre les deux écrivaines italiennes et du contact qu'elles ont toutes deux maintenu avec Benítez, nous tenterons de mettre en lumière des nouvelles dimensions des concepts de subalternité (subalternidad), d'autonomisation et de responsabilisation. Esther Benítez, traductrice très réputée du français et de l'italien (ce qui lui a valu le Premio Nacional de Traducción en 1992, en reconnaissance de toute son œuvre) en espagnol, a produit en parallèle un riche appareil critique (articles, préfaces, ateliers...), autant de sources paratextuelles dont nous extrayons les données traductologiques qui fondent notre étude.
\end{abstract}

\begin{abstract}
The multidisciplinarity of Translation Studies allows us to confront from other theoretical perspectives the phenomena that occur in the translation practice. Recent ideological trends broach the relationship between translation and gender. Surrounded by these approaches, the study observes the commitment that some women translators developed regarding the translation of women literature and the relationships that occur between woman authors and translators. Beginning with the definitions of empowerment (empoderamiento), in the field of cooperation and development, and also briefly examining works on entrustment (affidamento) and translation, this study focuses on Esther Benítez's work as translator of Anna Maria Ortese and Maria Antonietta Macciocchi. Benítez's translation is an excellent example of achievement via a collaboration network. The study also looks at new approaches to concepts such as subalternity (subalternidad), empowerment, entrustment, exploring the rapport between both Italian authors with Benítez. As a renowned translator in both French and Italian (which earned her the National Prize of Translation 1992, in recognition of her work), Esther Benítez also produced a rich critical corpus (articles, prefaces, workshops...), extratextual sources which offer valuable traductological information for this study.
\end{abstract}




\section{MOTS-CLÉS/KEYWORDS}

traduction et genre, autonomisation, responsabilisation, Esther Benítez, sources paratextuelles

translation and gender, empowerment, entrustment, Esther Benítez, extratextual sources

\section{Traducción y subalternidad como red colaborativa}

A partir de los años noventa, la línea descriptiva en traductología va evolucionando hacia posturas teóricas que se centran de forma más explícita en la idea de la manipulación, con una orientación más ideológica; se adoptan modelos menos formales, más culturales, especialmente atentos a las articulaciones del poder en el seno de todo (poli)sistema o cultura (Bassnett y Lefevere 1990).

Entre estas nuevas orientaciones destacan el poscolonialismo y el género, enfoques ambos donde encontramos el concepto de subalternidad, acuñado por Spivak (1988). Como desvelan sus estudios más sobresalientes en este campo (Spivak 1993) ${ }^{1}$, la subalternidad es una posición relativa, válida en todos los tipos de relaciones humanas (colectivas e individuales), siendo tal - el lugar del subalterno - bien por razones de raza, bien de clase o de género, o por todas esas razones a la vez.

Este punto nos permite entrar en materia para tratar la aplicación práctica y estratégica, de dichos enfoques - ejemplarizados en Spivak (1993) - e introducirnos en nuestro caso concreto, es decir, la observación de dichos aspectos traductológicos en la labor que Esther Benítez llevó a cabo con la traducción de la obra de Ortese.

Contra la neutralización de la diferencia, Spivak se posiciona - como de hecho veremos en Benítez -, a favor de un determinado grado de literalidad, de un discurso 'intermedio' que quiebre el efecto de inmediatez en la comprensión de la traducción, y ofrezca al lector la diferencia específica del original. A su vez, incluye intervenciones críticas que median entre el texto y el lector en lengua meta. Ambas posturas, extranjerización y uso de paratextos, lejos de ser contradictorias, se complementan y confluyen en el compromiso de la traducción (Simon 1996: 149). La documentación alternativa, paratextual, facilita el intercambio cultural entre el público lector y la diferencialidad del original, para "intentar dejar hablar al otro" a través del aparato traductológico: comentario, introducción, nota, glosario o anexo, así como artículos en revistas o monografías. El lector deja de ser figura 'pasiva' en su posición de absoluta comprensión, y pasa a participar activamente al tener que hacer un desplazamiento hacia la cultura origen y a su vez construir nuevas ideas a partir del paratexto que se le ofrece (Sales 2006: 26).

De nuestro estudio de los proyectos de traducción de la obra de Ortese llevados a cabo por Benítez, emerge en primer plano el papel activo y visible de la traductora. 'Proyectos' entendidos como conjunto de actitudes y decisiones a lo largo de todo el proceso de traducción, incluída la elección y/o selección del texto origen, pues sabemos por fuentes directas que la elección de Ortese y la selección de textos de esa autora, es autónoma con respecto a la iniciativa editorial ${ }^{2}$.

En Benítez, mantener el extrañamiento en la lectura responde a criterios preliminares de respeto por el original, y a la intención de 'movilizar' al lector hacia el texto y la cultura de origen, para lo que la traductora decide 'comprender lo escrito y lo no escrito' (iceberg del que habla Benítez en su nota preliminar a El Puerto de Toledo) antes de verter el texto a su lengua. De ahí surge su necesidad de desplazarse 
hasta el norte de Italia para trabajar con la autora, antes de dar por acabada la traducción.

Esta tendencia extranjerizante (Venuti 1992) se refleja claramente en las estrategias particulares ante problemas concretos. Esther Benítez - al igual que Spivak rastrea los matices lingüísticos y retóricos del texto origen, por ejemplo, las estrategias de traducción del léxico inventado - o ‘castellano' - en Ortese.

El original es un texto ya, de por sí, extranjerizante, que conduce al lector a otra realidad, a la vez propia y ajena, pretérita y extranjera. Es un texto exotizante: en el texto original de Ortese, Nápoles se transfigura en una ciudad española (herencia que persigue aún hoy a estos lugares) de nombre Toledo. Y aparece léxico en español, nombres de personas y cosas, topónimos, calles, nombres que no corresponden a la realidad de Nápoles - es léxico a menudo creado por la autora, españolizante -, y que tampoco corresponde a la realidad de nuestra lengua. Benítez practica el extrañamiento del extrañamiento: aplica una estrategia de 'inversión lingüística' para mantener la intención original de Ortese:

El primer escollo con que me encontré fueron las palabras castellanas que constelaban aquí y allá la novela. ¿Cómo dar la sensación de extrañeza que a un lector italiano le produce hallar incorporados al texto, sin cursiva ni indicación alguna que marque su extranjería, vocablos como 'despacho', 'barrio', 'mestizo', 'campesino' o 'héroes', tan ajenos a su comprensión como para nosotros studio, quartiere, meticcio, contadino o eroi? Tras mucho pensar, me incliné por el recurso inverso, pero a la vez idéntico: transformarlos en palabras italianas (buscando siempre, eso sí, la más próxima a nuestro romance, cuando había elección: es el caso de 'chiosco' preferido a 'edicola'). Lo mismo ocurría con los topónimos: 'Rua Ahorcados' es tan abstrusa para un italiano medio como para su equivalente español lo será 'Via degli Impiccati'... Mas si la autora quería ocultar sus significados, no me parecía lícito desvelarlos en la traducción con un trivial 'Calle de los Ahorcados'... En la novela, pues, todos los topónimos que aparecen en italiano, tenían un equivalente castellano en el original; $y$, a la inversa, los que se presentan en nuestra lengua, son traducción de los primitivos. (Benítez 1991: 8)

Además, con la inclusión del aparato crítico, paratextual, tanto para explicitar las estrategias aplicadas como para la reflexión crítica, la traductora crea un enlace entre la autora y el lector. Y a su vez, adquiere visibilidad. La visibilidad, intención omnipresente en Benítez, queda corroborada con la producción de artículos sobre los proyectos de traducción de Ortese, sobre la autora y sobre la disciplina misma.

Se desprende del contacto Benítez-Ortese que, para tender una red colaborativa hacia la posición subalterna, no basta la voluntad de la traductora: es necesaria la implicación de la propia autora. La comunicación entre autora y traductora es un "aspecto que Spivak valora enormemente, como diálogo que ha retroalimentado su praxis traductora y también su crítica literaria” (Sales 2006: 27).

En el caso de Benítez - Devi lo hará con Spivak (Sales 2006) -, Anna Maria Ortese, colabora con la traductora, cede ante la voluntad de ésta, se 'confía'... No sin cierta reticencia inicial, que nace probablemente de la dificultad por desalojar su lugar de no enunciación (humildad, rechazo a la popularidad, etc.). Se crea entre ambas una complicidad, una doble relación dentro de la cadena colaborativa entre dos polos. El polo (A) tiene la 'autoridad', entendida como poder de enunciación, control de recursos materiales o simbólicos, etc.; poder de difusión mediante la traducción en el caso de Benítez. El otro polo (B) es la posición subalterna, que se apoya en el primero 
para realizar el propio deseo en el mundo, para potenciarlo y para modificar el orden existente. Son dos fenómenos de desplazamiento: desde el polo A, desde la voluntad de agencia, hacia el $\mathrm{B}$, se produce una agencia de empoderamiento. En el sentido contrario, podemos reconocer en esa 'red colaborativa' el concepto de affidamento.

\subsection{Empoderamiento}

El empowerment, o empoderamiento, como paradigma de las teorías de cooperación y desarrollo, es el proceso (individual o colectivo) por el cual las personas fortalecen sus capacidades, confianza, visión y protagonismo, para impulsar cambios positivos en las situaciones en que viven:

El empoderamiento es una estrategia que propicia que los grupos marginados incrementen su poder, que accedan al uso y control de los recursos materiales y simbólicos, ganen influencia y participen en el cambio social. Esto significa tomar conciencia de los propios derechos, capacidades e intereses, y de cómo éstos se relacionan con los intereses de las otras personas, con el fin de participar desde una posición más sólida en la toma de decisiones y estar en condiciones de influir en ellas. (Pérez de Armiño 2000: 86)

Las estrategias políticas de género para el desarrollo de la mujer han sido las que más ampliamente han incorporado el concepto de empoderamiento. Es un proceso de cambio en el que las mujeres van aumentando su acceso al poder, y cuya consecuencia es la transformación de las relaciones desiguales entre los géneros, la reducción de la vulnerabilidad y el incremento de las propias capacidades, a medida que las mujeres adquieren y ejercen su derecho a satisfacer sus intereses prácticos y estratégicos ${ }^{3}$. Fue el movimiento DAWN, "Alternativas de Desarrollo con Mujeres para una Nueva Era”, el que primero lo planteó en los años 70. Y en los años 90, UNICEF desarrolló el primer enfoque sistemático del "Marco de igualdad y empoderamiento de las mujeres".

Gita Sen (1998), comprometida especialista en el análisis de los procesos de empoderamiento en relación con la superación de la pobreza, afirma que el empoderamiento es el proceso de ganar poder, tanto para controlar los recursos externos como para el crecimiento de la autoestima y capacidad interna. Empoderamiento supone, de hecho, cambios en las relaciones de poder en beneficio de un incremento de autoridad de algunas personas sobre sus propias vidas. "Si el poder significa control, el empoderamiento, por tanto, es el proceso de ganar control.” (Sen 1998: 121) Y de hecho, tanto en la dimensión individual como en la colectiva, "trabajar por el empoderamiento' implica, en primer lugar, ayudar a recuperar la autoestima.

Se habla de 'trabajar por el empoderamiento' a pesar de que su propia definición considera el fenómeno como reflexivo: "son las personas las que se empoderan a sí mismas" (Sen 1998: 127). Pero se presentan dificultades intrínsecas para que dicho proceso sea autogenerado espontáneamente, tales como el nivel de interiorización que los mensajes culturales o ideológicos de opresión y subordinación ocupan en la colectividad o individuo ${ }^{4}$. Esto conduce inevitablemente a considerar necesaria la existencia previa de un agente que promueva dicho fenómeno: bien sea un acontecimiento 'fortuito' lo que desata la propia conciencia en cuanto a la necesidad del empoderamiento; bien que el origen esté en políticas de desarrollo, en la acción de organizaciones de carácter humanitario que puedan catalizar el proceso o crear 
ambientes que apoyen el empoderamiento; o bien resida la agencia en la voluntad de un individuo 'capaz', consciente de las capacidades en potencia del 'otro', que pone a su servicio los medios materiales o simbólicos que contribuyen a "darles la posibilidad". Hablaremos por tanto, no de empoderamiento sino de agencia de empoderamiento, y llamaremos a esta figura "agente de empoderamiento".

\subsection{Affidamento}

Affidamento procede del verbo italiano affidare, que significa /confiar algo a alguien/ (ej.- la direzione è stata affidata al professore...; en español: encargar, conceder), o /confiar alguien a otra persona/ (ej.- in caso di divorzio il giudice deciderà affidare i figli alla madre; en español: dar la custodia), y es también válido como acción personal: affidare se stesso a qualcun'altro ( $e j .-$ mi affido alla provvidenza; en español: ponerse en manos de).

A principios de los años 90, el término affidamento es adoptado por Cigarini (1991; 1995a) y la Librería de Mujeres de Milán, grupo exponente del feminismo italiano de la diferencia. Con este término se denomina y connota la relación que implica: a) la confianza con la otra mujer que, más que el hombre, es la que puede ayudar a realizar nuestro deseo; b) la autoridad que le reconocemos a la otra, a su palabra y a su saber, y c) el significado de una relación reencontrada y modificada con la 'madre', en tanto que tendrán una consideración especial algunos conceptos como 'deuda simbólica'.

Como jurista, Cigarini ejemplifica el affidamento mediante "la abogada que [...] manifiesta confianza en el saber femenino asociándose con otra abogada mujer: ella sabe más que yo y puede hacer más eficaz mi deseo en el mundo (ganar una causa concreta)" (Cigarini 1995b).

Se trata de salir de la neutralidad y practicar la disparidad entre mujeres como "riqueza humana que hasta ahora pasaba y se quedaba en las relaciones privadas entre mujeres" (Cigarini 1995a: 130): una fuerza, un impulso, implícito por ejemplo en la relación madre-hija. En la necesaria existencia de esa disparidad entre mujeres, para desarrollar la noción de affidamento, Cigarini profundiza en otros conceptos como el de 'autoridad' y 'contrato' necesario (Cigarini 1992; 1994; 1995a):

Yo he sentido, desde el comienzo de mi opción de hacer política con mujeres, que el valor atribuido a otra (mujer) daba valor a mis deseos y a mí misma. Llamé affidamento a la relación con otra mujer para subrayar el más que a ella le atribuía ${ }^{5}$. (Cigarini 1995a: 133)

El más, la superioridad relativa atribuida a la otra mujer, es lo que crea la disparidad y lo que sienta las bases de una 'autoridad' y de una, siempre relativa, subalternidad.

La relación de affidamento, por tanto, es aquella que reconoce y acepta la relación vertical entre mujeres para, a partir de ésta, poder desarrollar conocimiento propio y no tener que adoptar el modelo ya existente, que es inevitablemente masculino (Muraro 1991: 2): “A la mujer con quien entro en relación de affidamento le reconozco autoridad femenina"6.

La autoridad femenina implica un ejercicio de libertad cuando este principio es aceptado y practicado eficazmente en la cotidianeidad, por ello es necesaria y conveniente una contratación explícita. El affidamento es, en este sentido contractual, una relación de intercambio, pero 
en la que el deseo parte de la que propone la relación ${ }^{7}$. Las críticas que acusan al affidamento de ser una práctica jerárquica basada en la dependencia son infundadas porque en el affidamento el deseo es de la mujer que lo propone, no de la otra [...] que lo fundamenta simbólicamente. Buscas quién puede reforzar tu deseo, o sea, te diriges hacia la que tenga una fuerza, un saber. (Cigarini 1995a: 154)

De ahí que el affidamento, como "acción de confiarse a" una persona con más autoridad, se produzca en un solo sentido, desde la subalternidad hacia la autoridad. Para el fenómeno que se produce en sentido inverso hemos aplicado el término de empoderamiento.

La delimitación del concepto se complica al considerar como prerrogativa el carácter espontáneo del deseo de la mujer que se 'affida' a otra y de la que parte la relación. Si el empoderamiento, en la práctica, rara vez es un fenómeno intrínseco - sino causado por un agente externo, que en primer lugar propiciará una autoestima y una toma de conciencia de las posibilidades de realizar un deseo - también la voluntad de affidamento será inducida, en algún modo, por la persona con autoridad (o mediador de ésta), por su ejemplo, su carisma, y su actitud de 'disponibilidad', hecho que conducirá a la posterior contratación.

Por otra parte, si el empoderamiento, desde el punto de vista del agente, consiste en poner a disposición un poder, un saber, un lugar de enunciación, unos medios,... desde el punto de vista del individuo (o grupo) que experimenta ese empoderamiento, se percibirá como un estímulo al compromiso. De aquí que ambos conceptos - affidamento y empoderamiento - se imbrican: la figura del agente de empoderamiento, generalmente una persona con autoridad, carisma, con capacidad de iniciativa y de transmisión de dicha iniciativa, así como de la responsabilidad que conlleva, coincide con la figura de autoridad en el affidamento.

En ambos casos - agencia de empoderamiento e inducción de affidamento - se pretende hacer causa común con la otra persona (otra mujer). De algún modo, entonces, el empoderamiento (agencia de empoderamiento) y el affidamento funcionan inversamente como actitudes y fenómenos de cooperación.

FIGURA 1

Empoderamiento y affidamento

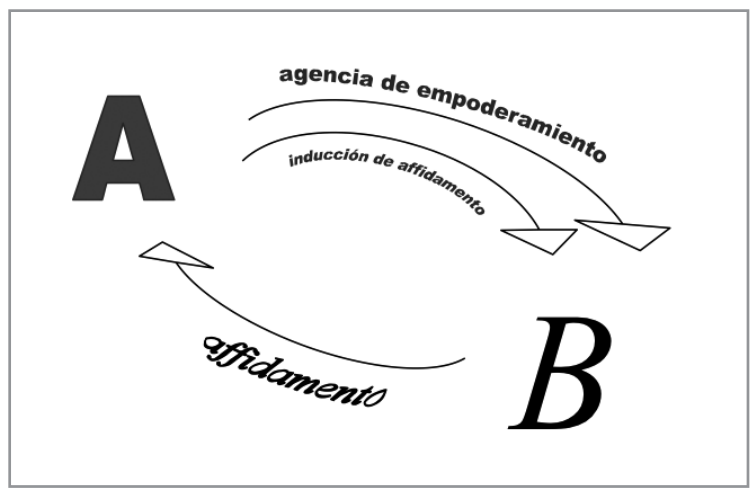


Para ofrecer un ejemplo, affidamento sería la relación especial que Benítez mantuvo con Consuelo Berges (1905-1988). Figura intelectual de relieve y biógrafa autodidacta, en el exilio durante varios años por sus preferencias republicanas, trabajó, entre otras cosas, por la igualdad de oportunidades para las mujeres. "Se honraba de pertenecer como socia honoraria de la Asociación de Mujeres Universitarias, era un dato que nunca olvidaba ella en sus currícula" (Benítez 1989). Como traductora (Descola, Proust, Saint-Simon, Flaubert, Stendhal), acompañó algunas de las muchas obras traducidas con prólogos y notas y luchó por obtener los derechos de autor de la traducción, como también ha hecho siempre Benítez.

Una joven Benítez se apoyaría en Berges, "nuestra decana” (Benítez 1977), para resucitar la APETI, fundada por Berges varias decadas antes para construir marcos legales, sociales, económicos, de referencia para la actividad de los traductores, para su representación en el mundo y su visibilidad ${ }^{8}$. Unidas en la vocación común por realizar esos deseos, pero dispares por edad, experiencia, capacidad de representación, consideramos affidamento la actitud de Benítez hacia Berges.

El resultado positivo de dicha relación fue, en efecto, la constitución de la nueva APETI (Asociación Profesional Española de Traductores e Intérpretes), la fundación de la ACET Asociación Colegial de Escritores (Sección Autónoma de Traductores), o la creación de la Fundación Consuelo Berges, sin olvidar la enorme actividad de Esther Benítez y su generación de traductores, que, gracias al sustento de las Asociaciones, pudieron llevar a cabo tantas iniciativas legales y sociales, así como congresos, conferencias y talleres en universidades, tanto en España como en el extranjero. La restitución a Berges por parte de Benítez: sin duda, ver realizadas sus antiguas aspiraciones.

Del mismo modo, o incluso en el sentido de grupo (Cigarini 1994; 1995a), podemos considerar affidamento la relación de Benítez con Hwang Ma Cé, conocida como Marcela de Juan (La Habana, 1905), traductora del chino, que trabajó como funcionaria en el Ministerio de Asuntos Exteriores y siempre vivió entre culturas.

Pero también sabemos que Benítez, procedente de El Ferrol, estableció muchas relaciones a traves de su tía materna, María Victoria Eiroa Díaz (cofundadora y directora del servicio exterior de la Sección Femenina de la Falange y posteriormente directora general de Promoción de la Familia y la Mujer, en la Transición), bajo cuya tutela estudió en Madrid y entre cuyas relaciones diplomáticas y amistades más cercanas se encontraba Marcela de Juan. Nos planteamos por tanto la posibilidad de que el empoderamiento de Benítez tuviera como origen la agencia de De Juan y de la misma Berges, lo que conduce siempre a la consideración de la relación como ciclo, como red.

Como decíamos al principio, parece difícil que se produzca el empoderamiento como acción estrictamente reflexiva y autónoma. Se contemplará el concepto a partir de la necesidad de un agente de empoderamiento.

Y el affidamento habrá de ser contemplado, igualmente, partiendo de la posibilidad de que exista una inducción previa por parte del individuo con autoridad.

Sabemos que no sólo de mujeres recogió Benítez esa especie de testigo que lleva a un compromiso en la traducción y sería imposible, por lo muy reductivo, encuadrar la labor conjunta de la traductora en la 'traducción feminista'. Pero en los instrumentos de análisis expuestos en la primera parte de este artículo encontramos motivos para reconstruir lazos entre ella y algunas de sus autoras, en concreto con Anna Maria Ortese, a la que por tanto volvemos, y con Maria Antonietta Macciocchi. La sucesión 
y correlación de dichos factores nos inducen a considerar las propuestas de traducir a estas autoras como red para rescatar al subalterno, y aún más, para reivindicar la figura de la mujer, es decir, como un caso de traducción y género.

\section{Benítez y la subalternidad}

Para profundizar en el concepto de subalternidad tal y como lo vemos reflejado en la práctica traductora y crítica de Benítez, hemos de considerar subalterno, en primer lugar, al mismo traductor, o como diría Sáenz (1993: 2), ese

simple 'recodificador' pasivo, que se somete al autor, aferrándose a un concepto metafísico de la obra original, a la que reconoce una posición sagrada. El traductor, personaje casi siempre apocado (según Ortega [1937/1956: 12]) y por lo general más bien melancólico y dubitativo (según Monterroso [1985: 90]) asume conscientemente su complejo de inferioridad y siente que la relación entre la obra del autor y su traducción está protegida por el más fuerte de los tabúes.

Precisamente, abolir esa fosilizada jerarquía, uno de los puntos fuertes de los enfoques post-estructuralistas en traducción - junto con la valoración del traductor como figura ideológicamente marcada, no neutral -, es una de las apuestas por las que Benítez se batió con mayor tesón, y consiste en vindicar la visibilidad del traductor, sus derechos y su identidad social y cultural.

En segundo lugar, con su labor, el traductor consigue dar voz al autor extranjero, que de otro modo seguiría siendo desconocido para la cultura meta. Benítez forma parte del conjunto de traductoras que, en palabras de Sales (2006: 25) "deciden traducir a autoras por las que sienten especial admiración, o cuyos proyectos les parecen especialmente interesantes en términos éticos y/o estéticos", por lo que ponen su 'poder' a disposición de una autora y una obra. Esta operación de enunciación y existencia significa la reivindicación de la voz, tanto por parte del subalterno como por ese agente (la traductora) implicado éticamente en promover que dicha voz ocupe el lugar enunciativo, reconocido como tal, del que carece (Spivak 1999).

Sintetizamos en el siguiente cuadro esa doble posición de Esther Benítez ante el subalterno:

FIGURA 2

Benítez y la subalternidad

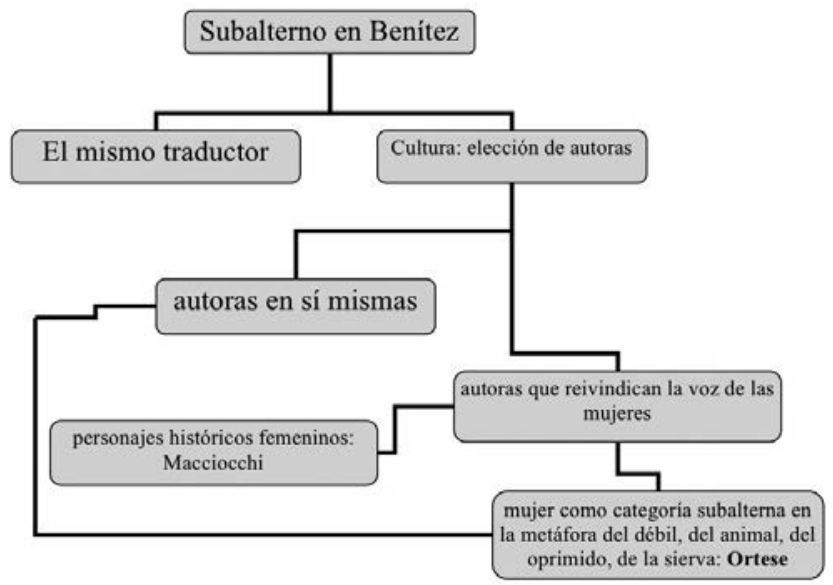


Contamos, por un lado, con la lucha de Benítez por la profesión del traductor y, por otro, con su labor reivindicativa de la difusión de la literatura y la cultura mediante la elección de sus autores. Pero vemos además que, como en Spivak, contamos con casos ejemplares de esa labor en la traducción de escritoras que, a su vez, reivindican la voz y memoria de las mujeres: Spivak traductora - Devi autora - voz de las mujeres tribales de Bengala.

Este tipo de dinámicas con frecuencia se producen en cadena. En primera instancia, la propia Devi establece una agencia de empoderamiento al "dar voz en bengalí (una lengua nacional en la India) y por escrito a las historias orales de mujeres tribales que se comunican en lenguas sumamente minorizadas" (Sales 2006: 28). A partir del mismo fenómeno nos adentraremos en Macciocchi, que da relevancia histórica a personajes femeninos, y en Ortese, que da voz al débil, al oprimido.

Por tanto, Benítez ofrece al lector de lengua española una sensibilidad 'necesaria' que procede de otro polisistema: "las voces no uniformadas que no lograrían pasar unos filtros extraliterarios cada vez más restrictivos con el solo motor de las fuerzas del mercado" (Benítez 1998), y por lo que, dentro de nuestro estudio, Ortese y Macciocchi serán consideradas subalternas.

Veamos cuáles son las características de la vida y la obra de estas dos autoras, en cuya edición española juega un papel determinante la traductora.

\subsection{Anna Maria Ortese}

Anna Maria Ortese, olvidada periódicamente, y periódicamente redescubierta, extranjera en su propio país, procedía de un sur pobre, el de sus recuerdos de infancia y adolescencia. Nació en Roma en 1914, pero pasó su adolescencia y juventud en Nápoles - su 'Toledo' imaginario - y Trípoli. Siempre sintió la falta de raíces y, tras muchos viajes, habitó un modesto apartamento en Rapallo (Liguria), donde viviría su exilio personal. La búsqueda de raíces en las ciudades de sus abuelos, Barcelona y Carrara, la conducirá más al sueño que a los recuerdos.

Abandona la escuela a los catorce años pero seguirá sus estudios en solitario con los libros de los hermanos ${ }^{9}$ aprendiendo por sí misma el francés y el español. De vuelta a Italia, los hermanos varones marcharán lejos, a América, a Australia.

En el barrio del puerto, en Nápoles, la joven, quinta hermana de una familia que comparte una única habitación, descubre las obras de los románticos ingleses, Poe, Mansfield. En 1933, a la muerte de su hermano Manuel (primero de una larga serie de duelos), se despierta su deseo de escribir y Massimo Bontempelli, maestro del realismo mágico, la ayudará cuatro años más tarde a publicar una recopilación de relatos incomprendidos, Angelici dolori.

Desde entonces, y sobre todo a partir de Il mare non bagna Napoli, premio Viareggio en 1953, la obra de Anna Maria Ortese oscilará entre un realismo fantástico, donde se mezclan figuras alegóricas, seres inocentes en un mundo regido por el mal, y el neorealismo al que son atribuidos los cuentos-reportajes y encuestas para diferentes periódicos, ya que dan una imagen de la desolación del Sur.

En su vida habrá dolor y pobreza, incluso indigencia, pero será rescatada por el ensueño y la imaginación. El momento capital de este recorrido vital y literario será L'iguana, considerada la obra maestra de la autora y una de las principales obras de la literatura italiana del S. XX, que aparecerá una primera vez en 1965 y será reeditada 
a mediados de los 80. Con "esta novela corta, fábula tierna y misteriosa, Ortese desenmascara la novela exótica hispanoamericana que en aquel tiempo vivía su boom” (Varanini 2000).

Figura apartada, ajena a la notoriedad de las buenas reseñas, Ortese obtiene esporádicos reconocimientos (Premio Strega 1967), pero el éxito llega sólo cuando en los años ochenta un editor de moda, Adelphi, lanza algunas obras tardías, que no añaden mucho a lo escrito con anterioridad.

Y de hecho, Adelphi publicará también sus viejas obras, entre ellas L'Iguana, que en 1988 aparece en francés, con Gallimard. En aquella ocasión, excepcionalmente, Ortese acepta la entrevista de Le Monde. Cuando la entrevistadora llega a su modesta casa de Rapallo, donde vive desde hace diez años con su hermana mayor, la escritora ya está arrepentida, y sus pocas palabras serán: "Non ho più niente da dire"10.

Lectora de Schopenhauer, Ortese supone la existencia de un nirvana más allá de la desesperación, pero en su calidad de autodidacta rechaza posiciones filosóficas más consolidadas.

No se casará nunca, - "sono sempre stata sola, come un gatto".

Escribe para sí misma, día tras día, para controlar la angustia y salvar los dos problemas principales para ella, sobrevivir y expresarse con las palabras: "Si scrive perché si cerca compagnia, poi si pubblica perché gli editori danno un po' di denaro". ${ }^{11}$

En su última etapa - tras In sonno e in veglia (1987), con la gran novela Il cardillo addolorato (1994) o su último libro, Alonso e $i$ visionari (1996) - desarrolla un exilio interior, marcado por terribles y persistentes dificultades materiales:

el dinero se convierte en símbolo de la crueldad, y de la encarnación misma, es decir, del divorcio entre la materia oscura y un alma incapaz de transcender su propio fracaso sin la ayuda de la Estética, entendida por Ortese como forma nueva de unidad, capaz de reconciliar la presencia del ser en el mundo y su incontenible aspiración a un más allá. (Simeone 1991)

El marasmo social y político de la Italia moderna y el triunfo del cinismo encerrarán a Anna Maria Ortese, al final de su vida,

en una soledad visionaria tal vez desmedida, aunque jamás sus capacidades de transfiguración ni la gracia casi salvage de su imaginario fueron atentadas por los sufrimientos de una vida errante. Ella ha atravesado su siglo con irregularidad, intransigencia y fraternidad. Si Ortese rompe con la modernidad, es a causa de un deseo de profundidades más ardientes: A me piangeva il cuore lo sgomento della solitudine, della ormai evidentissima inutilità mia di fronte alla vita pratica, alla civiltà moderna ${ }^{12}$. (Simeone 1991)

Su aislamiento y su inaccesibilidad esconden en realidad una vida plena de relaciones culturales y sentimentales, estrechas e imprevisibles relaciones con personajes célebres - escritores, intelectuales, políticos de primer plano, hombres de espectáculo - y grandes amigos desconocidos. Una vida aventurera, dominada por el demonio de la fuga, una vida vagabunda abanderada por la literatura, constelada de más de veinte volúmenes y centenares de artículos periodísticos de los que la misma autora había perdido la memoria. Emerge un recorrido imprevisible, orgulloso y coherente en su fascinante marginalidad. 


\subsection{Maria Antonietta Macciocchi}

Maria Antonietta Macciocchi nació en 1922 en una pequeña ciudad del Lacio; en 1942 se adhiere al Partido Comunista Italiano y en 1950 obtiene la licenciatura en Historia del Arte, en la Universidad La Sapienza de Roma. Junto a su compañero Pietro Amendola, periodista y futuro diputado del PCI, se desplaza a Nápoles, donde ambos encarnaron el modelo de la pareja progresista. De su relación nace su hija Giorgina. Una vez separada, Macciocchi se casa con el periodista Alberto Jacoviello, del que posteriormente se divorcia.

Entre 1956 y 1961 dirige la publicación semanal feminista y comunista Noi donne y entre 1961 y 1968 la revista, también comunista, Vie nuove. Más tarde será redactora estelar y corresponsal, en Argel, Bruselas y París, de l'Unità, la voz oficial del Partido Comunista Italiano, para el que entrevistó a las grandes figuras de la izquierda de la época (Tito, Mitterrand, Guy Mollet, Jruschov, Indira Gandhi, Ben Bella). En 1968 es elegida diputada por el PCI, pero en 1971 entra en desacuerdo con la línea oficial del partido. Esas diferencias con el PCI se plasmaron en su controvertida obra sobre la revolución cultural china de Mao Zedong y en una carta-libro a Louis Althusser (Cartas desde el interior del PCI, 1968), un texto influido por el maoísmo y la incipiente revuelta cultural francesa.

Deja su actividad en el Parlamento y se traslada a París en 1972, donde consigue el doctorado en Ciencias Políticas en La Sorbona y obtiene un lectorado en Sociología en la muy izquierdista Universidad de París VIII. En 1977, momento crucial de los "años de plomo" italianos, regresa a Italia para instalarse en Bolonia. Como epicentro de los nuevos movimientos izquierdistas antiautoritarios, Bolonia constituía la "base natural" de los simpatizantes de las Brigadas Rojas. Enrico Berlinguer, secretario general del PCI, se opuso a la violencia e intentó cerrar cualquier contacto con las Brigadas Rojas. Esa política implicó la expulsión de Macciocchi.

Se adhiere al Partido Radical y es elegida en 1979 para la Cámara de los Diputados y el Parlamento Europeo. Será europarlamentaria entre 1984 y 1989 con la izquierda independiente.

Emigraría de nuevo. Esta vez hacia el Partido Socialista de Bettino Craxi, por su desacuerdo con el "compromiso histórico" entre el PCI y la Democracia Cristiana de Giulio Andreotti. Colabora con los diarios Corriere della Sera, Le Monde y El País. En 1992 tiene un encuentro con el papa Juan Pablo II y queda fascinada por él. Fruto de ese descubrimiento fue el libro Las mujeres, según Wojtyla.

Promueve la Convención de Venecia de los intelectuales europeos y en 1986 recibe del gobierno francés la Ordre des Arts et des Lettres. Ese mismo año fue condecorada por François Mitterand con la Legión de Honor francesa.

Ha publicado una quincena de libros, principalmente sobre temas internos del movimiento revolucionario italiano y europeo. Los últimos los dedicó a las dos mayores exponentes femeninas de la República Napolitana, Eleonora de Fonseca Pimentel (1752-1799) y Luisa Sanfelice Molina (1764-1800), ambas víctimas de la "ferocia misogina dei crocesegnati, o sanfedisti" (Macciocchi 1999)13.

La suya fue una existencia honesta, concluida en el desencanto. Pasó sus últimos años en una casa rural de Sabaudia, ajena por completo a la política. Allí murió a los 85 años (Morodo 1989; González 2007). 


\section{Sobre la consideración de Ortese y Macciocchi como subalterno}

En nuestro estudio es significativo, en primer lugar, el hecho de que la traductora 'elija' los autores que traduce. Como la misma Benítez comenta en fuentes paratextuales (Benítez 1995), ése es un lujo que pocos traductores pueden permitirse, y que ella ha podido llevar a cabo sólo en algunos casos: Pavese, Boccaccio, Zola,... Proponer a una editorial la publicación de una obra que no es de fácil lectura, que no corresponde a los gustos dominantes del público, por estilo o por temática, o cuya edición no ha sido rentable en lengua original, resulta una acción impregnada de contenido ideológico. Responde a un compromiso y a una "autoridad" por parte del traductor.

En el caso de Benítez, son escritoras - Ortese y Macciocchi - que, aun siendo de reconocido prestigio, son poco publicadas y leídas, y se mantienen en la subalternidad respecto a la cultura de masa, bien por el estilo literario, siempre en los márgenes de las modas, bien por la incómoda temática.

Valga como ejemplo la reflexión que hace Macciocchi (1997) en los incisos a lo largo de su narración sobre la historia de Luisa Sanfelice:

Se hace necesaria una pausa de reflexión. [Luisa] poco a poco se ha disuelto en la nada. Es la suerte de muchas. Aumentan las santas. Disminuyen las criaturas femeninas de ingenio. [...] Para la historia es como si ella no hubiera existido. También por esta razón trabajo testarudamente contra el machismo de los italianos, historiadores incluidos [...]. Los hombres italianos, educados en esto por las propias madres, han dudado siempre, y siguen sospechando, de la rectitud y de la honestidad de las mujeres que se dedican a la acción, y aún más a la política. Los estudiosos se sienten dignos depositarios del verbo revolucionario. Pero es sobretodo un verbo masculino. [Ellos] han olvidado a estas mujeres, laceradas y arrancadas fuera de la memoria"14. (nuestra traducción)

Una vez descubierto el inquietante paratexto de la misma Ortese a la última edición italiana de Il porto di Toledo (1998) y la relación de Benítez con Ortese (prólogo español a El puerto de Toledo, 1991), el nexo con que contamos para relacionar a Ortese y Macciocchi lo hayamos en la obra ya citada sobre Sanfelice (Macciocchi 1997). La autora dedicó el libro sobre La vera storia di Luisa Sanfelice e della Repubblica napoletana del 1799, L'amante della Rivoluzione "a Anna Maria Ortese, che mi ha incitato a scrivere questo "libro necesario" su Luisa Sanfelice, "incredibile, inocente, generosa figura".

En el libro, mediante una labor de investigación in situ narrada paso a paso, Macciocchi rescata a esta mujer y su historia de la ignorancia y simplificación a la que había quedado relegada, a pesar de haber sido tratada por grandes estudiosos como Benedetto Croce.

Podemos deducir a partir de esta obra de Macciocchi el porqué del interés de Ortese en que dicho libro fuera escrito, pues contribuye a la recuperación de la figura de Sanfelice,

en polémica con tantos historiadores 'buenistas' y rancios que, no obstante su erudición, no la consideran digna de atención. Ahora [...] de Luisa hablan como si estuviera viva. Al levantar los ojos, aparece tras las rejas - ¿no será una alucinación recurrente en mi búsqueda? [...] La Sanfelice, en la memoria popular, representa el anillo de conjunción entre la historia de una revolución, como la de Nápoles, y el Risorgimento: Luisa es la mítica Fenix, una mujer que renace de sus propias cenizas, eternamente, para acompañar los grandes momentos de la historia ${ }^{15}$. (nuestra traducción) 
Benítez tradujo de Macciocchi en 1987 Dos mil años de felicidad y en 1988 La mujer de la maleta: viaje intelectual de una mujer en Europa. Poco más tarde, en 1991, traducirá El puerto de Toledo de Annamaria Ortese y de la misma autora El colorín afligido, en 1995.

Nuestra hipótesis es que Macciocchi, que estableció con su traductora una relación de gran amistad - como atestigua la rica correspondencia entre ellas, correspondencia no sólo de carácter profesional, sino personal y familiar -, impulsó la traducción al español de Ortese, indujo a Benítez a trabajar con su obra, hipótesis "muy probable dada la admiración de Macciocchi por Ortese y la profunda estima hacia Benítez. Macciocchi habría podido 'sugerir' a Benítez la traducción de la obra de Ortese, por su lengua soberbia y valiosa"16 (nuestra traducción), según Giorgina Amendola ${ }^{17}$.

Con las dos, ambas premio Strega de literatura, mantuvo contacto Benítez durante su trabajo de traducción.

No sabemos en qué fecha se inicia la relación Ortese-Macciocchi. Las dos escritoras se conocieron probablemente a través de la revista mensual Noi donne, publicación histórica de la izquierda italiana en los años setenta, con sus batallas contra las discriminaciones, por la igualdad de salario, por el divorcio, el aborto, la tutela de la maternidad. Annamaria Ortese y Maria Antonietta Macciocchi participaron en la revista activamente junto con otras figuras de renombre: Ada Gobetti, Marguerite Duras, Giovanna Pajetta... (Taglietti 2000).

Ambas estaban vinculadas al sur y, aunque pertenecientes a generaciones distintas, mantuvieron un contacto intelectual y de mutua admiración. Hay una lejana afinidad marcada por intereses comunes, pues la obra de Macciocchi y la de Ortese, a pesar de las diferencias, tienen en común un punto fuerte, que las vincula más allá de su relación personal: la clara intención de dar voz al subalterno. En Macciocchi, a personajes históricos, como Luisa Sanfelice o Eleonora Fonseca Pimentel ${ }^{18}$, mujeres, revolucionarias, mártires. En Ortese, a seres marginales - la marginalidad del emigrante, del oprimido, de la sierva, del animal, en definitiva del débil -, generalmente encarnados en una figura femenina y en cierto modo autobiográfica, lo que constituye un claro ejemplo de subalterno por género, pero también por estilo literario: no comercial, fantasmagórico, inasible.

A pesar de ser considerada por la crítica una de las escritoras italianas más interesantes del S. XX, prevalecen en la trayectoria de Ortese - jalonada de vez en cuando por algún premio literario - los años de ostracismo, de silencio, de melancólicos fracasos editoriales. "Mantenerse fiel a la literatura en estas condiciones, también existencialmente dramáticas, resulta heroico y constituye en sí un testimonio esplendido del sentido de la escritura y de la escritura en relación con la vida"19 (Mazzocchi 1997, nuestra traducción).

Anna Maria Ortese crea con su escritura un espacio transcultural imaginario, de orígenes españoles que, por otro lado, también se dejan sentir en las figuras femeninas de Macciocchi, Eleonora Fonseca Pimentel y Luisa Sanfelice Molina.

Il porto di Toledo, tendrá tres ediciones en lengua original: las dos primeras con Rizzoli (Milano), en 1975 y 1985; la tercera con Adelphi (Milano), en 1998. Entre las dos últimas, Alfaguara publica su traducción en España: El puerto de Toledo, 1991. Y en 1995, con Anagrama, sale El colorín afligido. Ambas traducciones, como hemos visto, son de Esther Benítez ${ }^{20}$, y propuestas por ella misma. 
Un dato interesante de su implicación con la subalternidad es que, a punto de aparecer esta tercera edición italiana de El Puerto de Toledo, Ortese, que sintió siempre amor-odio por esta obra - "se trata de una novela que rechazo... pero a la que amo aún” (Benítez 1991: 9) -, la retoma y escribe un fascinante prefacio (Ortese 1998), fechado en marzo de 1998, pocos días antes de su muerte.

Desde que escribió Il porto di Toledo, Ortese dedicaba la obra a la memoria de Anne Hurdle, pero la escritora no ofrecía ninguna explicación sobre la identidad de la mujer, ni en la primera edición (Rizzoli, 1975) ni en la sucesiva (Rizzoli, 1985). Sólo en la reciente reedición del libro en italiano (Adelphi, 1998) decide hacer explícita la dedicatoria de su novela a Anne: Ortese desvela el misterio que encierra este nombre. "Aggiunte e mutamenti"21, la nueva introducción-dedicatoria, es toda una reivindicación del subalterno en la figura de esta mujer, joven inglesa de veintitrés años que fue condenada a muerte en el Londres de finales del S. XVIII por cometer un delito de falsificación ${ }^{22}$. Durante el proceso, la mujer, no teniendo voz para defenderse, "permaneció callada" y sólo antes de morir "lanzó un largo grito. El único de su vida". La escritora, invirtiendo los parámetros corrientes de Justicia y Delito, absuelve a Anne Hurdle y condena, en cambio, a un mundo que no sólo no le ha ofrecido la posibilidad de vivir dignamente, sino que además le ha robado su pequeña vida. Con su prefacio - y con su obra -, Ortese reivindica el "Regno dell'Espressività" para todos los seres humanos que no tienen palabra ni voz.

Es un prefacio que corresponde a la misma pulsión que las declaraciones de la autora en manifestaciones en Roma (1989) sobre la marginalidad del inmigrante con el que, tal vez influenciada por su etapa en Libia, se identifica - por su sensibilidad hacia el oprimido:

La historia de la vida de las mujeres está llena de silencios, de gritos inhumanos, a veces, pero normalmente de silencio... El silencio es proprio de quien no tiene el valor o no le es reconocido por parte del poder...¿Para qué hablar, si su voz llega como un sonido confuso en el viento? (Ortese 1998: 14, nuestra traducción) ${ }^{23}$.

El texto de Ortese repropone el tema de la posibilidad de hacer hablar a los excluidos, "quelli che non si salvano nell'Espressione" (Ortese 1998: 14).

Podría bastar, por tanto, esta última edición de la novela, para captar dos momentos importantes y fundamentales de su obra: Ortese plasma un recorrido de vida y de vocación literaria al margen de los límites impuestos por los cánones de la Realidad - que, en sus propias palabras, es pura mentira - y, al mismo tiempo, da voz a una humilde protagonista de la no-historia (Mazzocchi 1997; Nardella 1998).

No deja de despertar curiosidad el hecho de que Ortese, en los últimos días de su vida, decida manifestar con claridad su reivindicación, necesidad que, aun presente en las anteriores ediciones, vivía en la oscuridad de su dedicatoria. Entre las dos últimas ediciones italianas 'ocurre' la historia que une a estas tres mujeres (Macciocchi, Benítez, Ortese), cartas, encuentros e influencias. Podríamos incluso preguntarnos si Benítez y Ortese llegaron a hablar, al tratar de la traducción de la obra al español, sobre el misterio que encerraba la simple dedicatoria "A Anne". La pregunta cae en el vacío, pero tal vez es innecesario hacerla. El prólogo de Ortese, que lógicamente no aparece en la versión española por ser ésta anterior a la última edición italiana, se nos ofrece como testamento de vida de la autora. 
Del mismo modo, con su primer gran fracaso, L'Iguana (1965), elabora, mediante una red de metáforas tímidas y astutas, una poética en defensa de lo superfluo, del débil y de lo ridículo; de aquello que procede de los girones más bajos de la humanidad, contra la lógica de los victoriosos, contra la arrogancia perfumada de las pelucas en los salones aristocráticos, contra la desmesura de las imágenes televisivas. Opone a todo ello, con convicción, su cuento y sus poéticas imágenes de la inanidad. (Haas 1994: 114, nuestra traducción)

Todo ello configura la personalidad de una autora subalterna, y similares consideraciones hacemos sobre la figura de Macciocchi, cuyos artículos y novelas denuncian que la opresión del elemento femenino sería un dato estructural de la sociedad occidental, y que sólo mediante una acción política y social organizada puede la mujer emanciparse.

Macciocchi, con sus viajes fugaces, con sus incisivos artículos, con su radicalismo humanista, su anticonvencionalismo militante y agresivo, su feminismo atípico, configura un continuum incansable de lucidez y provocación.

Todo se entremezcla en ella mediterráneamente: su adolescencia garibaldina nunca acabada, de resistente y partisana, y su pasión irreductible marcarán su proyecto intelectual y vital, así como un humanismo solidario y libre, en contra de reducciones y de fronteras interiores y exteriores. Una personalidad compleja, contradictoria y asilvestrada para unos, independiente y tierna para otros, y, para todos, entusiasta y polémica. (Morodo 1989)

Macciocchi entiende la política como ética de compromiso social e intelectual. Maria Antonietta, con su maleta, recorrerá países, tomará el pulso de sociedades lejanas y exóticas, hablará y discutirá con grandes personajes de la política y de la cultura. Pasará de entender Europa como reducción y limitación, como la expresión tecnocrática de la lógica del capital, a ejercer un activo proselitismo progresista por una Europa abierta y sin fronteras. De agitadora cultural y de parlamentaria europea radical, con Gramsci y Althusser como ejes críticos, pasa al replanteamiento vital. De la ilusión al desencanto del mayo de 1968; de la protesta, al proceso y ruptura con el comunismo italiano ${ }^{24}$.

En esa etapa de revisión autocrítica y reconversión europeísta, con su último libro, La mujer de la maleta, traducido en España por Esther Benítez, Maria Antonietta expresa, junto al desasosiego colectivo de los últimos 50 años europeos, la necesidad de encontrar señas de identidad que afiancen tradición y modernidad: fascismo y antifascismo, optimismo revolucionario y desencanto privatizador, denuncia de los intelectuales orgánicos y elogio de la imaginación contestataria. Todo esto se perfila con ironía sutil, desenfado estival y optimismo tolerante. En el marco de estas contradicciones y tentativas de superación, la razón o el genio europeos van abriéndose caminos. Incluso, como provocación final y divertida, Maria Antonietta Macciocchi integrará misticismo, europeísmo y feminismo (la creencia gozosa, según ella, del papa Wojtyla en el daimon de la mujer) o su aventura anticipatoria de la Europa del Atlántico a los Urales.

Macciocchi abre y amplía fronteras por su testimonio humano de comprensión y permanente lucha por la libertad. 


\section{Conclusión}

A nuestro entender, la clave para que una relación pueda ser considerada affidamento (en sentido lato usado por Cigarini) está en ese verbo 'buscar': buscar "quién puede reforzar tu deseo, o sea [dirigirte] hacia la que tenga una fuerza, un saber" (Cigarini 1995a: 154). Ésa es la acción que dará inicio a la relación de affidamento.

Si utilizamos uno de nuestros ejemplos, Benítez busca a Berges ("recurrimos a ella como mentora" [Benítez 1989]), por lo que claramente se trata de affidamento, aunque nos consta que cuando Benítez acude a Berges para expresar e intentar cumplir su deseo, es decir, proponer la formación de una asociación de traductores a la persona que para ella es la decana moral de los traductores, descubre con sorpresa, por la misma Consuelo Berges, que APETI ya existió, que ella misma la fundó junto con Marcela de Juan y que puede contar con su apoyo para que la vieja asociación sea resucitada (Benítez 1989). Se da inicio a una relación con un objetivo claro: "cuatro entusiastas, capitaneados por Consuelo Berges, resucitamos una moribunda APETI, que sólo recuperó 15 miembros de sus viejos adheridos" (Benítez 1992: 32). Esther Benítez se apoya en la experiencia de Berges. En este caso tan evidente, ambas tienen la misma profesión, ambas son traductoras: una propone su deseo, la otra tiene la 'autoridad'.

Sin embargo, al aplicar el concepto de affidamento, como ya importado por Sales (2006), a la relación entre escritora y traductora, del mismo modo que, en la práctica, la escritora (Devi) no 'busca' a la traductora (Spivak), Ortese no busca a Benítez. Pertenecen a profesiones diferentes y a diferentes polisistemas, por lo que la condición de 'subalternidad' relativa de Ortese respecto a Benítez no es inmediata. Su relación se proyecta, más bien, en un eje trasversal que tiene en cuenta las múltiples articulaciones de ambos polisistemas (origen y meta) y de los recovecos de las operaciones interculturales. De modo que nos situamos en el complejo ámbito de la comunicación intercultural y, esta vez, dentro de la misma Europa, donde el fenómeno de la subalternidad parece menos evidente - aunque la realidad lo desmiente en cuanto a género - que en los contextos de poscolonialismo (en Spivak y Devi se confrontan la cultura occidental colonizadora y la 'tercermundista' India colonizada), para cuyo estudio hemos de recurrir a la matización y desarrollo aplicado de los conceptos de base.

Teniendo en cuenta esta dimensión de los conceptos de autoridad y subalterno podemos hablar de affidamento. Y matizamos, un affidamento inducido: la mujer con autoridad tiene los medios para hacer que el deseo de la subalterna se cumpla. Lleva a cabo acciones de estímulo en pro del empoderamiento de la subalterna. Entonces la otra persona, se mueve hacia la de autoridad y contrata... pacta y colabora: se affida.

Y de nuevo, la inducción de affidamento se solapa con la agencia de empoderamiento. En realidad, los roles son coincidentes: la mujer que propone el affidamento para realizar su deseo (concreto) desea, en abstracto, empoderarse; la mujer agente de empoderamiento coincide con la mujer con autoridad que induce el affidamento.

En términos generales, hablar de empoderamiento significará tener en cuenta su bilateralidad y, por tanto, incluirá en su noción tanto la agencia de empoderamiento como el empoderamiento en sí. Y al hablar de affidamento, tendremos en cuenta que dicho término describe en general la reciprocidad de los fenómenos de inducción de affidamento y el affidamento en sí.

Dentro de lo posible, pues no debemos olvidar que ante todo se trata de relaciones humanas, y que como tales son un continuum de desplazamientos que pueden 
llegar a tejer una compleja trama, queremos cerrar este artículo reconstruyendo y sintetizando una red colaborativa entre nuestras autoras. Introducimos, pues, el siguiente cuadro cronológico:

CUADRO 1

Cronología comparada

\begin{tabular}{|l|l|l|l|}
\hline & Benítez traduce... & Macciocchi escribe... & Ortese escribe... \\
\hline en 1987 & $\begin{array}{l}\text { Macciocchi: Dos mil años } \\
\text { de felicidad (1983) }\end{array}$ & $\begin{array}{l}\text { La donna con la valigia } \\
\text { maleta (en Italia se publica } \\
\text { en 1989) }\end{array}$ & \\
\hline en 1988 & $\begin{array}{l}\text { Macciocchi: La mujer de la } \\
\text { Ortese: El puerto de Toledo }\end{array}$ & & \\
\hline en 1993 & & Cara Eleonora & \\
\hline en 1995 & Ortese: El colorín afligido & $\begin{array}{l}\text { inducida por Ortese (que ha } \\
\text { leído Cara Eleonora), La vera } \\
\text { storia di Luisa Sanfelice }\end{array}$ & \\
\hline en 1997 & & & $\begin{array}{l}\text { el prefacio Anne, le } \\
\text { aggiunte, i mutamenti }\end{array}$ \\
\hline en 1998 & & & \\
\hline
\end{tabular}

Ortese, subalterna en su marginalidad, tanto por su vida como por identificación con el débil en su obra, no logra el merecido reconocimiento en su país - ni tal vez fuera -, pero es, sin embargo, una autora traducida.

Hemos visto cómo, en España, su obra ha podido ser conocida a través de las traducciones, principalmente, de Esther Benítez ${ }^{25}$. La traductora, que mantenía estrecho contacto con la literatura italiana, especialmente con editores y personalidades del mundo de la cultura ${ }^{26}$, para recabar información sobre autores 'de interés' para su trabajo, recibía sin duda las sugerencias de Macciocchi (de la que Benítez ya había traducido dos obras), entre las que no podía faltar Ortese.

Pues bien, Macciocchi resulta mediadora del empoderamiento de Ortese, empoderamiento del cual es agente Benítez. Ortese se 'affida' a Benítez y colabora en la traducción de El Puerto de Toledo. Posteriormente, Macciocchi recibirá estímulo creativo de Ortese, que la incita a seguir excavando y escribiendo sobre 'mujeres' revolucionarias. Es decir, Ortese es agente de empoderamiento hacia Macciocchi, la induce a escribir sobre Sanfelice.

El papel de la traductora en todo el proceso es de catalización en dos sentidos. Por un lado es transmisora de la sensibilidad intelectual y vital de las dos escritoras italianas a un sistema extranjero, el español; por otro, de esta operación resulta el empoderamiento de ambas autoras y su obra, también en el sistema origen y en el más amplio sentido de campo literario. A través de la traducción como operación ideológica, Benítez contribuye a la consolidación del peso cultural de Ortese y de Macciocchi.

Parece que, al final de su vida, Ortese siente la necesidad de dar voz a Anne Hurdle, paradigma de la mujer subalterna, a la que, de forma velada siempre había dedicado su novela, y escribe el prólogo de El Puerto de Toledo. Desvela su identidad y la defiende, habla por ella y por todas las mujeres que han sido históricamente privadas de voz. 
FIGURA 3

Benítez, Ortese, Macciocchi

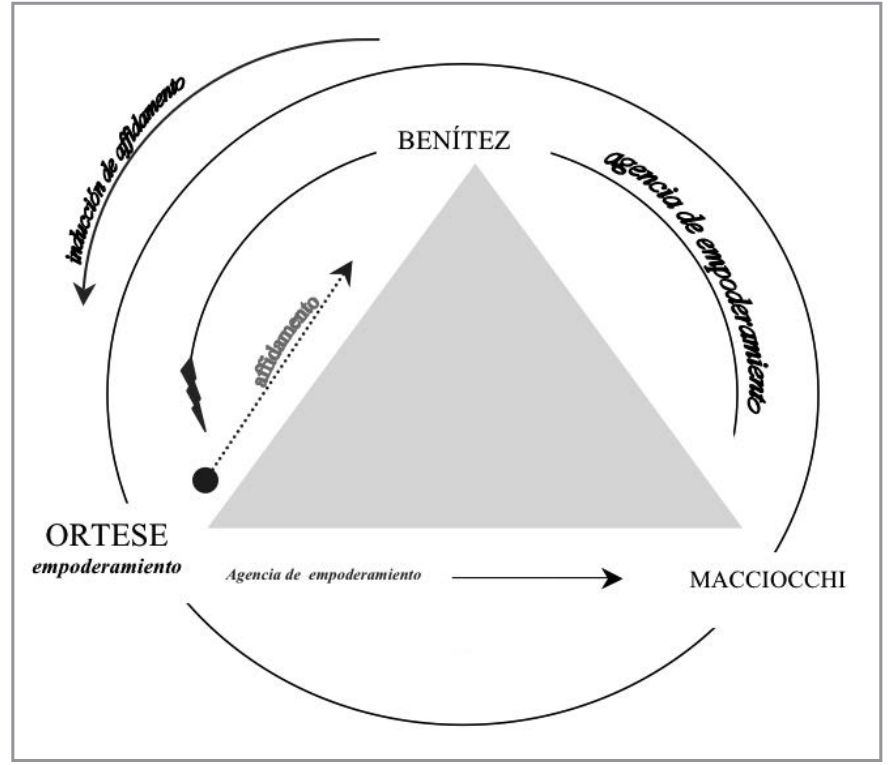

En definitiva, podemos concluir que no es casual que sea en el ámbito de la traducción donde Spivak desarrolla su teoría sobre la subalternidad; que conceptos, como empoderamiento y affidamento, importados de otros ámbitos, convergen en la consolidación del concepto de subalternidad en traductología y, a su vez, lo articulan para ofrecer nuevos instrumentos de análisis.

Que la fuerza de este concepto trasciende los enfoques tradicionales de disparidad entre 'mundos' o culturas, y puede ser observado con nitidez en ámbitos muy cercanos, en que la mujer, por ser paradigma de la maternidad, ha de claudicar ante una jerarquía de roles que le imprimen la inferioridad.

Que tampoco es casual que, a pesar de la difusión mediática de las políticas contra la violencia de género y de la teórica emancipación de la mujer en Occidente, también aquí la hegemonía masculina y la inferioridad del infiel son promulgadas desde el mismo púlpito.

Finalmente, que la traducción es vehículo y aún más, motor, en que cobran sentido las relaciones humanas y los movimientos culturales de nuestra civilización. Es en el interior de la traductología, así contemplada, donde la figura de Esther Benítez nos ofrece su pleno sentido.

\section{NOTAS}

1. Nos referimos en particular a los trabajos de Spivak, que representan y abanderan la lucha contra las tendencias homogeneizantes occidentales en torno a la traducción. Es, según Sales (2006: 27), mediante sus traducciones y comentarios de la autora bengalí Mahasweta Devi con lo que "Spivak ha hecho más que ningún otro crítico con vistas a articular las historias y demandas de las mujeres subalternas con un compromiso político que siempre ha quedado templado por una conciencia precisa de los límites éticos de tal proyecto".

2. Entrevista oral con Isaac Montero y Mauro Hernández, marido e hijo de Esther Benítez (octubre de 2007). 
3. Esta manera de entender el empoderamiento de las mujeres no identifica el poder en términos de dominación sobre otros, sino como el incremento por las mujeres de su autoestima, capacidades, educación, información y derechos; en definitiva, como el control de diversos recursos fundamentales con objeto de poder influir en los procesos de desarrollo.

4. Motivo por el que hablamos de la reticencia inicial de Ortese a la colaboración.

5. La cursiva en "más" es nuestra.

6. La autoridad femenina no replica a la autoridad tradicional porque no busca poder social dentro del orden patriarcal. Tal y como dice Bochetti (1996), autoridad difiere de poder porque la autoridad es reconocida libremente por la mujer que desea entrar en relación con otra mujer; en cambio, el poder es impuesto. En conclusión, la autoridad es la capacidad de acuerdos que evalúan y potencian la relación de affidamento entre dos mujeres (Muraro 1991).

7. Entendemos por 'intercambio' dentro de una relación de affidamento el concepto de restitución o pago de la deuda simbólica (Cigarini 1995a: 160), que - no basta un reconocimiento verbal - ha de ser traducido en prácticas sociales reconocibles por parte de la mujer o grupo al que se está pagando la deuda.

8. Berges funda APETI en 1955, junto con Marcela de Juan, "de la que gustaba denominarse la eminencia gris/roja. [...] Desaparecida Marcela en 1981, me traspasó el cuidado de amplificar cuanto su ronca voz no le permitía gritar a voces” (Benítez 1989: 264).

9. Evidencia de la condición de inferioridad de género.

10. "No tengo más nada que decir". (nuestra traducción)

11. "Se escribe porque se busca compañía, luego se publica porque los editores dan algo de dinero". (nuestra traducción)

12. "Me lloraba el corazón desesperada de soledad, a causa de mi ya evidentísima inutilidad frente a la vida práctica, a la civilización moderna”. (nuestra traducción)

13. Los "sanfedistas" eran las bandas armadas del movimiento popular contra la República napolitana de 1799. El Sanfedismo, estaba formado por masas campesinas y bandidos, organizados en torno al cardenal Fabrizio Dionigi Ruffo.

14. "Si rende necesaria una pausa di riflessione. (Luisa) pian piano si è dissolta nel nulla. È la sorte di tante. Aumentano le sante. Diminuiscono le creature femminili d’ingegno. [...] Per la storia è come se lei non fosse esistita. Anche per questa ragione lavoro testardamente contro il "machismo" degli italiani, storici compresi [...]. Gli uomini italiani, educati in ciò dalle stesse madri, hanno sempre dubitato, e continuano a sospettare, della rettitudine e dell'onestà delle donne che si danno all'azione, e sopratutto alla politica. Gli studiosi si sentono onesti depositari del verbo revolucionario. Ma è soprattutto un verbo maschile. [Loro] hanno dimenticato queste donne, lacerate e strappate via dalla memoria" (Macciocchi 1997: 127).

15. "In polemica con tanti storici perbenisti e bigotti che, nonnostante la loro erudizione, non la considerano degna di attenzione. Ora [...] di Luisa parliamo come se fosse viva. Alzando gli occhi compare, dietro le grate - ma non è un allucinazione ricorrente in questa mia ricerca? [...] La Sanfelice, nella memoria popolare, rappresenta l'anello di congiunzione tra la storia di una rivoluzione, come quella di Napoli, e il Risorgimento: Luisa è la mitica Fenice, una donna che rinasce dalle proprie ceneri, in eterno, per accompagnare i grandi momenti della storia" (Macciocchi 1997: 133).

16. "molto plausibile data l'ammirazione di Macciocchi per Ortese e la profonda stima in Benítez. Macciocchi avrebbe potuto "sugerire" a Benítez di cimentarsi con le traduzioni degli scritti della Ortese, dalla lingua superba e preziosa” (Carta de Giorgina Amendola del 6 de junio de 2008, en respuesta a la mía del 22 de mayo).

17. No es posible recurrir a la información de primera mano: Anna María Ortese moría en marzo de 1998. Esther Benítez, en mayo de 2001. Y Maria Antonieta Macciocchi, en abril de 2007. Contamos en cambio con los los testimonios más directos, la familia de Benítez, la de Macciocchi.

18. Macсіосснi, Maria Antonietta (1993): Cara Eleonora. Milano: Rizzoli.

19. "Restare fedeli alla letteratura in queste condizioni, com'è noto anche esistenzialmente drammatiche, ha avuto dell'eroico, e costituisce già in sé una splendida testimonianza del senso dello scrivere, dello scrivere in rapporto al vivere" (Mazzocchi 1997: 90).

20. Además Ortese había sido traducida al español anteriormente por Juan Ramón MAsoliver Martínez (1969): La Iguana. Barcelona: Ediciones Destino; y María José Jaular Aulet (1989): Entre vela y sueño. Barcelona: Ediciones Versal.

21. Por Aggiunte e mutamenti se entiende el delito de falsificación ("adición y suplantación”), entendido como estafa. 
22. De Anne Hurdle sólo había constancia a través de los Diarios de Benjamín Constant, una breve página en la que se identifica con ella y su desgracia (Benjamin Constant (1979): Euvres. Editions Gallimard. Collection de la Pléiade "Journaux Intimes", 262). Hemos acudido al profesor Wenceslao-Carlos Lozano (UGR), experto en Constant, que ha proporcionado nuevas claves sobre el personaje, y nos ha puesto en contacto con el profesor Dennis Wood. Ambos han compartido generosamente los resultados de sus indagaciones sobre Constant y la figura de Ann Hurle, llamada por Ortese Anne Hurdle (Wood 1982).

23. "La storia della vita delle donne è piena di silenzi, di grida disumane, a volte, ma più spesso di silenzio... Il silenzio è proprio di chi non ha valore o non gli è riconosciuto dal potere...Perché parlerebbe, se la sua voce è intesa solo come un suono confuso nel vento?” (Ortese 1998: 14)

24. Macciocchi, Maria Antonietta (1978): Dopo Marx. Milano: Libri dell'Espresso.

25. Aunque Ortese había sido traducida al español anteriormente por Juan Ramón Masoliver ( $L a$ Iguana, Barcelona: Ediciones Destino, 1969), y María José Jaular Aulet (Entre vela y sueño, Barcelona: Ediciones Versal, 1989), difícilmente pudo partir del ámbito editorial español una propuesta que ya se había demostrado poco rentable.

26. Hay, en su correspondencia privada, constancia de dichos viajes y encuentros de carácter profesional, a la búsqueda de autores.

\section{REFERENCIAS BIBLIOGRÁFICAS}

Bassnett, Susan y Lefevere, André, eds. (1990): Translation, History and Culture. London/ New York: Pinter.

Benítez, Esther (1989): En recuerdo de Consuelo Berges. Cuadernos de Traducción e Interpretación. 11-12:261-267.

Benítez, Esther (1992): La situación del traductor profesional (en España). In: Purificación FERnÁndez Nistal, ed., Estudios de traducción: inglés/español. Valladolid: Instituto de Ciencias de la Educación, 23-32.

Benítez, Esther (1995): Preguntas y respuestas. Quimera. 140:42-45.

Bocchetti, Alessandra (1996): Lo que quiere una mujer. (Traducido por Maite Larrauri) Madrid: Cátedra.

Cigarini, Lia (1994): La Autoridad femenina. Encuentro con Lia Cigarini. Duoda. Revista d'Estudis Feministas. 7:55-82.

Cigarini, Lia (1995a): La autoridad femenina. In: Lia Cigarini, ed. La política del deseo. Barcelona: Icaria, 123-178.

Cigarini, Lia (1995b): Libertad femenina y norma. Duoda: Revista d'estudis feministes. 8:85-107.

HaAs, Franz (1994): Anna Maria Ortese: Il cardillo addolorato. Belfagor. 49(1):111-115 Firenze. Librería de Mujeres de Milán (1991): No creas tener derechos. Madrid: Horas y horas.

Macciocchi, Maria Antonietta (1997): L'amante della Rivoluzione. La vera storia di Luisa Sanfelice e della Repubblica Napoletana del 1799. Milano: Mondadori.

Mazzocchi, Giuseppe (1997): Anna Maria Ortese e l'ispanita. Modern Language Notes. 112(1):90-104.

Monterroso, Augusto (1985): La Palabra mágica. Barcelona: Muchnik.

Muraro, Luisa (1991): La politica é la politica delle donne. Via Dogana, Rivista di practica politica. 1:2-3.

Nardella, Rosa (1998): Anna Maria Ortese: l'opera in fieri. Cuadernos de Filología Italiana. 5:291-309.

Ortega y GAsset, José (1937/1956): Miseria y esplendor de la traducción / Elend und Glanz der Übersetzung. Munich: LangewiescheBrandt.

Pérez de Armiño, Karlos, eds. (2000): Diccionario de Acción humanitaria y Cooperación al desarrollo. Consultado el 3 de enero 2010, <http://dicc.hegoa.efaber.net/listar/mostrar/86>.

SÁenz, Miguel (1993): Autor y Traductor. In: Eizie (Asociación de Traductores, Correctores e Intérpretes de Lengua Vasca). Consultado el 3 de enero de 2010, <http://pymes.wanadoo.es/eizie/euskara/argital/senez/14/saenz.htm>.

Sales Salvador, Dora (2006): Traducción, género y poscolonialismo. Compromiso traductológico como mediación y affidamento femenino. Quaderns: Revista de traducció. 13:21-30. 
SEN, Gita (1998): El empoderamiento como un enfoque de pobreza. In: Irma Arriagada y Carmen Torres, eds. Género y Pobreza, Nuevas Dimensiones. Santiago de Chile: ISIS Internacional, 121-139.

Simon, Sherry (1996): Gender in Translation. Cultural Identity and the Politics of Transmission. London/New York: Routledge.

SPIVAK, Gayatri Chakravorty (1988): Can the subaltern speak? In: Lawrence Grossberg y Cary NeLson, eds. Marxist Interpretations of Literature and Culture: Limits, Frontiers, Boundaries. Urbana: University of Illinois, 271-313.

SpIVAK, Gayatri Chakravorty (1993): The Politics of Translation. In: Outside in the Teaching Machine. New York, Routledge, 179-200

SPIVAK, Gayatri Chakravorty (1999): A Critique of Postcolonial Reason. Toward a History of the Vanishing Present. Cambridge/London: Harvard University Press.

Varanini, Francesco (2000): Anna Maria Ortese. Autori da salvare. Consultado el 3 de enero de 2010, <http://www.eseresi.it/ri_ortese.htm >.

Venuti, Lawrence (1992): Rethinking Translation: Discourse, Subjectivity, Ideology. London: Routledge

Wood, Dennis (1982): Constant and the case of Anne Hurle. French Studies Bulletin. 5:6-8.

\section{ANEXOS}

Benítez, Esther (8 de junio de 1977): Traducir en el desierto. El País.

Benítez, Esther (1991): Prólogo. In: Anna Maria Ortese, El puerto de Toledo. Barcelona: Anagrama. 7-9.

Benítez, Esther (29 de augusto de 1998): Traducción y política cultural. El Mundo (opinión).

Cigarini, Lia (1991): Notas sobre la autoridad femenina. Madrigale 4. Avizora. Consultado el 3 de Enero 2010, <http://www.avizora.com/publicaciones/la_mujer_y_su_mundo/textos/ 0054_libertad_femenina_norma.htm>).

GonzÁlez, Enric (17 de abril de 2007): Maria Antonietta Macciocchi, controvertida política italiana. El País. Consultado el 3 de enero de 2010, <http://www.elpais.com/articulo/agenda/ Maria/Antonietta/Macciocchi/controvertida/politica/italiana/elpepigen/20070417elpepiage - $7 /$ Tes/>.

Macciocchi, Maria Antonietta (17 de febrero de 1999): Altamura. La strage delle innocenti. Corriere della Sera. 33.

Morodo, Raúl (21 de enero de 1989): Macciocchi o la aventura de una Europa sin fronteras. Una mujer vitalista. El País. Consultado el 3 de enero de 2010, $<$ http://www.elpais.com/articulo/cultura/MACCIOCCHI/MARiA_ANTONIETTA/

FASCISMO/Macciocchi/aventura/Europa/fronteras/elpepicul/19890121elpepicul_2/Tes/>.

Ortese, Anna Maria (1998): Il Porto di Toledo. Milano: Adelphi.

Ortese, Anna Maria (1991): El puerto de Toledo. Madrid: Alfaguara.

Simeone, Bernard (1991): La Survivante (prefacio). In: Anna Maria Ortese. La Lune sur le mur. Verdier: Lagrasse. Consultado el 3 de enero 2010, <http://www.editions-verdier.fr/v3/ auteur-ortese.html>. 